\title{
Leukemia Inhibitory Factor Promotes Neural Stem Cell Self-Renewal in the Adult Brain
}

\author{
Sylvian Bauer and Paul H. Patterson \\ Biology Division, California Institute of Technology, Pasadena, California 91125
}

\begin{abstract}
Although neural stem cells (NSCs) persist in various areas of the adult brain, their contribution to brain repair after injury is very limited. Treatment with exogenous growth factors can mitigate this limitation, suggesting that the brain environment is normally deficient in permissive cues and that it may be possible to stimulate the latent regenerative potential of endogenous progenitors with appropriate signals. We analyzed the effects of overexpressing the cytokine leukemia inhibitory factor (LIF) on adult neurogenesis in the normal brain. We found that LIF reduces neurogenesis in the olfactory bulb and subventricular zone by acting directly on NSCs. LIF appears to promote NSC self-renewal, preventing the emergence of more differentiated cell types. This ultimately leads to an expansion of the NSC pool. Our results have implications for the development of therapeutic strategies for brain repair and suggest that LIF may be useful, in combination with other factors, in promoting regeneration in the adult brain.
\end{abstract}

Key words: IL-6; CNTF; adult neurogenesis; stem cell niche; brain repair; IdU; CldU

\section{Introduction}

The adult brain contains multipotent neural stem cells (NSCs) and committed progenitors that participate in brain repair, albeit to a very limited extent (Magavi et al., 2000; Arvidsson et al., 2002; Nakatomi et al., 2002). It may be possible to stimulate brain repair from endogenous precursors in the injured brain by finding conditions that will unleash and channel this dormant potential.

Many types of injuries to the nervous system are accompanied by a rapid and transient increased expression of leukemia inhibitory factor (LIF) (Banner and Patterson, 1994; Banner et al., 1997; Jankowsky and Patterson, 1999; Suzuki et al., 2000; Minami et al., 2002; Bauer et al., 2003; Sriram et al., 2004). In this context, LIF is known to regulate neuronal phenotype (Rao et al., 1993; Corness et al., 1996; Sun and Zigmond, 1996; Holmberg and Patterson, 2006) and coordinate the astrocyte, oligodendrocyte, microglia, and inflammatory cell responses (Sugiura et al., 2000; Kerr and Patterson, 2004, 2005; Holmberg and Patterson, 2006). Importantly, LIF is required for the lesion-induced proliferation of neuronal progenitors in the regenerating adult olfactory epi-

Received July 18, 2006; revised 0ct. 15, 2006; accepted 0ct. $17,2006$.

This work was supported by a fellowship from The John Douglas French Alzheimer's Foundation (S.B.) and by grants from the National Institute of Neurological Disorders and Stroke and the McGrath Foundation (P.H.P.). We are grateful to D. McDowell, B. Kennedy, and members of the California Institute of Technology Office of Laboratory Animal Resources for their excellent assistance. We also thank F. H. Gage (The Salk Institute, San Diego, CA) for the generous gift of the retroviral plasmids and N. L. Nadon (National Institute on Aging, Bethesda, MD) for the 16month-old $\mathrm{C57BL} / 6 \mathrm{~J}$ mice. We are grateful to $C$. Charrier for help with the neurosphere culture and to A. Lukaszewicz for critical reading of this manuscript.

Correspondence should be addressed to Paul H. Patterson, Biology Division, 216-76, California Institute of Technology, 1200 E. California Boulevard, Pasadena, CA 91125. E-mail: php@caltech.edu.

S. Bauer's present address: Physiologie Neurovégétative, Unité Mixte de Recherche 6153, Centre National de la Recherche Scientifique-1147 Institut National de la Recherche Agronomique, Université Paul Cézanne-AixMarseille-3, Avenue Escadrille Normandie-Niemen, BP 351-352, 13397 Marseille Cedex 20, France.

D01:10.1523/JNEUROSCI.3047-06.2006

Copyright $\odot 2006$ Society for Neuroscience ～0270-6474/06/2612089-11\$15.00/0 thelium (Bauer et al., 2003), suggesting that LIF may promote neurogenesis after other types of injury.

LIF is a member of the cytokine family that signals through the heterodimeric glycoprotein 130 (gp130)/LIF receptor (LIFR) complex, which also includes ciliary neurotrophic factor (CNTF), interleukin (IL)-6, IL-11, OSM (oncostatin M), CT-1 (cardiotrophin-1), and CLC/NNT-1 (cardiotrophin-like cytokine/novel neurotrophin-1) (Heinrich et al., 2003). LIF signaling activates the Jak (Janus kinase)/STAT (signal transducer and activator of transcription) and MAP (mitogen-activated protein) kinase pathways, which promote astrogliogenesis in vitro (Bonni et al., 1997; Molne et al., 2000; Viti et al., 2003; Chang et al., 2004; Barnabe-Heider et al., 2005; He et al., 2005). In addition, LIF is well known for promoting mouse embryonic stem (ES) cell selfrenewal (Williams et al., 1988) and the long-term growth of embryonic human NSCs in culture (Wright et al., 2003). Other reports indicate that LIF signaling supports the maintenance/ self-renewal of cultured mouse embryonic NSCs (Shimazaki et al., 2001; Pitman et al., 2004; Bonaguidi et al., 2005; Gregg and Weiss, 2005), possibly by activating Notch signaling (Chojnacki et al., 2003). However, little is known about the influence of LIF signaling on NSCs and neurogenesis in vivo: gp130 regulates cellcycle reentry of embryonic cortical progenitors (Hatta et al., 2002), and exogenous CNTF enhances neurogenesis in the adult brain (Emsley and Hagg, 2003; Kokoeva et al., 2005).

To clarify the effects of LIF on NSCs and neurogenesis in vivo, we overexpressed LIF in the uninjured, adult mouse forebrain. In contrast to CNTF (Emsley and Hagg, 2003; Kokoeva et al., 2005), we find that exogenous LIF reduces neurogenesis in the subventricular zone (SVZ)/olfactory bulb (OB) system. This is attributable, in part, to a direct effect of LIF on adult NSCs: LIF maintains them in a loop of symmetric/self-renewing divisions in vivo, which prevents the emergence of more differentiated progeny. LIF ultimately increases the pool of NSCs, which could be ex- 
ploited to accelerate the regeneration of the SVZ. Our data suggest that LIF may be useful for cell replacement in situ.

\section{Materials and Methods}

Animals. We used adult male C57BL/6J mice of various ages. In the first experiment, 16-month-old animals were obtained from the National Institute on Aging and our own breeding colonies and were injected with recombinant adenoviruses (see below). All other experiments were performed on 2- to 6-month-old animals obtained from The Jackson Laboratory (Bar Harbor, ME). All experiments were approved by the California Institute of Technology Institutional Animal Care and Use Committee.

Bromodeoxyuridine. Bromodeoxyuridine (BrdU; Sigma, St. Louis, $\mathrm{MO}$ ) was dissolved in $0.9 \% \mathrm{NaCl}$, sterile filtered, and injected intraperitoneally $(100 \mathrm{mg} / \mathrm{kg})$ according to the protocols indicated below.

Adenovirus injection. Recombinant adenoviruses $\left(\approx 2.7 \times 10^{6} \mathrm{pfu}\right.$ in 3 $\mu \mathrm{l}$ of sterile PBS) encoding LacZ (Ad:LacZ) or LIF (Ad:LIF) (Zhu et al., $2001)$ were injected into the right lateral ventricle $(-0.1 \mathrm{~mm}$ anteroposterior relative to bregma, $0.9 \mathrm{~mm}$ lateral from the midline, and $2.5 \mathrm{~mm}$ below the dura) using a $5 \mu$ l Hamilton syringe attached to a 28 -gauge needle. Injections were performed over 3-5 min, and the needle was left in place for another 6-10 min before withdrawal.

In the first experiment, mice were injected with Ad:LIF or Ad:LacZ ( $n=5$ per group) and received single BrdU injections for $7 \mathrm{~d}$, starting 2 weeks after adenovirus injection. These mice were killed 2 weeks after the first BrdU injection ( 1 week after the last BrdU injection and 4 weeks after adenovirus injection).

Other mice were killed 3 weeks after adenovirus injection and were used to obtain SVZ-derived neurospheres or to assess long-term, labelretaining cells in the SVZ (see below).

Retrovirus production and injections. A replication-incompetent green fluorescent protein (GFP) retrovirus, pseudotyped with vesicular stomatitis virus glycoprotein $\mathrm{G}$ (VSV-G), was produced according to published methods. Human embryonic kidney 293 (HEK293) cells were transiently transfected with plasmids containing gag-pol and $v s v-g$ under the control of the cytomegalovirus (CMV) promoter and the virus plasmid (pNIT) containing long-terminal repeat-driven GFP (a gift from F. H. Gage, The Salk Institute, San Diego, CA), using Polyfect (Qiagen, Valencia, CA). Medium containing viral particles was collected 40 and $64 \mathrm{~h}$ after transfection and centrifuged each day at $50,000 \times g$ for $2 \mathrm{~h}$ at $4^{\circ} \mathrm{C}($ Beckman centrifuge model L8-M, rotor SW-28; Beckman Coulter, Fullerton, CA). Pellets obtained after each centrifugation were resuspended in sterile PBS, mixed together, and centrifuged again. The final pellet was resuspended in $200 \mu \mathrm{l}$ of sterile PBS (concentrated by a factor of 1800), aliquoted, and stored at $-80^{\circ} \mathrm{C}$. Titer was determined to be $>1 \times 10^{7} \mathrm{cfu}$ (colony-forming units)/ml using HEK293 cells.

The GFP retrovirus was injected bilaterally into the SVZ of 2-monthold mice. Three injections of $400 \mathrm{nl}$ each were performed per SVZ using a $1 \mu \mathrm{l}$ Hamilton syringe attached to a beveled glass micropipette $(\approx 14$ $\mu \mathrm{m}$ inner diameter) at the following coordinates [anterior relative to bregma, lateral, depth below the dura (in $\mathrm{mm}$ ) ]: 0, 2, 2; 0.5, 1.2, 2.2; and $1,1,2$. Immediately after the injection of the GFP retrovirus, animals received an injection of Ad:LIF or Ad:LacZ ( $n=2$ in each group) into the right lateral ventricle.

SVZ regeneration. Cytosine- $\beta$-D-arabinofuranoside (AraC; $2 \%$; Sigma) in saline was infused for $6 \mathrm{~d}$ into the lateral ventricle (same coordinates as for adenovirus injection) using osmotic mini-pumps (model 1007D, Alzet; Durect, Cupertino, CA) implanted subcutaneously on the back of the animals and connected to a brain infusion kit 2 or 3 cannula (Alzet)

Recombinant mouse LIF protein (Millipore, Billerica, MA), human epidermal growth factor (EGF; Invitrogen, Carlsbad, CA), or PBS [with or without bovine serum albumin (BSA)] were infused before or after AraC using mini-pump model 1003D (for 1 and $3 \mathrm{~d} ; 1 \mu \mathrm{l} / \mathrm{h}$ ) or 1007D (for $7 \mathrm{~d} ; 0.5 \mu \mathrm{l} / \mathrm{h}$; Alzet). Mini-pumps were filled with LIF protein diluted in PBS $(5 \mu \mathrm{g} / \mathrm{ml})$, resulting in the delivery of 60 or $120 \mathrm{ng}$ of LIF per day (for pump models 1007D and 1003D, respectively). EGF $(16.67 \mu \mathrm{g} / \mathrm{ml}$ ) was dissolved in PBS containing 0.1\% BSA and infused at $400 \mathrm{ng} / \mathrm{d}$, similar to other studies (Shimazaki et al., 2001; Doetsch et al., 2002).
Mice ( $n=3$ per group and per experiment) were killed at 1,3 , or $7 \mathrm{~d}$ after AraC removal, 1-2 h after a single BrdU injection.

Double nucleoside administration. Mice (2 months of age) were given iododeoxyuridine (IdU) or chlorodeoxyuridine (CldU) (both from Sigma) in their drinking water $(1 \mathrm{mg} / \mathrm{ml})$, supplemented with $2.5 \% \mathrm{su}-$ crose. The solution was made fresh and changed daily.

IdU was administered first for 2 weeks, followed by 1 week with regular water containing no marker. Animals were then injected with Ad:LIF or Ad:LacZ in the lateral ventricle $(n=3$ per group) and treated on the following day with $\mathrm{CldU}$ for another 2 weeks. Animals were perfused after 1 more week with regular water containing no marker (i.e., a total of 4 weeks after the end of IdU treatment). All animals drank similar amounts of water throughout the treatment period (an average of 5.5 $\mathrm{ml} / \mathrm{d})$.

Tissue processing and histology. Animals were perfused transcardially with $0.1 \mathrm{M}$ phosphate buffer (PB), $\mathrm{pH} 7.5$, followed by fresh, cold $4 \%$ paraformaldehyde in $\mathrm{PB}$. Brains were dissected and fixed another $3-5 \mathrm{~h}$ at $4^{\circ} \mathrm{C}$, washed overnight in $\mathrm{PB}$ at $4^{\circ} \mathrm{C}$, and immersed overnight at $4^{\circ} \mathrm{C}$ in $\mathrm{PB}$ containing 20\% sucrose. Brains were then embedded in freezing media (optimum cutting temperature), frozen in chilled isopentane $\left(-25^{\circ} \mathrm{C}\right)$, and stored at $-80^{\circ} \mathrm{C}$ until sectioning.

Coronal brain sections $(14 \mu \mathrm{m})$ were collected on Superfrost Plus slides (Fisher Scientific, Pittsburgh, PA) using a cryostat (model CM3050; Leica Microsystems, Bannockburn, IL) and dried overnight at room temperature before being stored at $-20^{\circ} \mathrm{C}$.

Immunohistochemical staining was performed according to standard procedures. Staining for BrdU and double staining for IdU and CldU were as described previously (Bauer and Patterson, 2005). The primary antibodies used were mouse anti-NeuN (Millipore), mouse anti-Ki67 and anti-mammalian achaete-scute homolog 1 (Mash1) (both from BD Biosciences PharMingen, San Jose, CA), rabbit anti-LIFR and goat antidoublecortin (Dcx) (both from Santa Cruz Biotechnology, Santa Cruz, CA), sheep anti-EGF receptor (EGFR; Millipore), rabbit anti-GFP (Invitrogen), rabbit anti-S100 (Dako, Carpinteria, CA), rabbit antiphosphorylated Stat3 (Y705; Cell Signaling Technology, Beverly, MA), goat anti-Olig2 (R \& D Systems, Minneapolis, MN), and rat or mouse anti-BrdU (Oxford Biotechnology, Oxfordshire, UK and BD Biosciences PharMingen, respectively). Species-specific secondary antibodies conjugated to Alexa 488, 568, or 633 were from Invitrogen.

Quantification and image analysis. Staining was analyzed with a Nikon (Tokyo, Japan) microscope (model Diaphot 300) and an LSM510 confocal microscope (Zeiss, Thornwood, NY) equipped with an argon/krypton laser $(488 \mathrm{~nm})$, two helium/neon lasers (543 and $633 \mathrm{~nm})$, and a Coherent (Santa Clara, CA) Chameleon two-photon laser [used at 725 $\mathrm{nm}$ to image DAPI (4',6'-diamidino-2-phenylindole dihydrochloride) staining]. Pictures were obtained with a Spot RT Slider camera and associated software (version 3.4; Diagnostic Instruments, Sterling Heights, MI) or with the LSM software (Zeiss). Colocalizations were investigated by performing $z$-stack acquisitions and three-dimensional reconstructions. Adobe Photoshop version 7.0.1 (Adobe Systems, San Jose, CA) was used to adjust contrast and brightness.

Sections sampled at similar anatomical levels of the OB or the SVZ (between +0.3 and $+0.7 \mathrm{~mm}$ anterior relative to bregma) were processed at the same time for each type of staining. Quantification was performed at the confocal microscope or with the Nikon microscope using a $40 \times$ or an oil-immersion $63 \times$ objective. Single and double-labeled cells were hand scored in various structures of interest by an observer blind to the treatment of the animals. Cells were quantified on two to six equally spaced $(42 \mu \mathrm{m})$ sections per animal. Cell numbers are expressed as mean \pm SEM per section for each structure (no difference in the size of the OB or SVZ was observed between animals from different experimental groups).

For image analysis of the Dcx and GFP staining, black-and-white pictures of three to four equally spaced $(42 \mu \mathrm{m})$ sections per animal were taken with the Nikon microscope using constant settings across various animals from the same experiment. Image analysis was performed using the NIH ImageJ software (version 1.34s) by quantifying the staining area after adjusting the threshold manually. Results are expressed as mean \pm SEM pixel $^{2}$ per section. 
Neurosphere cultures and quantification. Neurospheres were obtained from micro-dissected adult mouse SVZ (Doetsch et al., 1999a). SVZ fragments were digested in papain (Sigma) and trypsin (Invitrogen) solution for $20 \mathrm{~min}$ at $37^{\circ} \mathrm{C}$ and mechanically dissociated by passing through a 26-gauge needle (Charrier et al., 2006). Single cells were seeded at 10 cells per microliter in 24-well plates (500 microliters per well) in serum-free media consisting of DMEM supplemented with B27, penicil$\mathrm{lin} /$ streptomycin, $20 \mathrm{ng} / \mathrm{ml} \mathrm{EGF}$ with or without $10 \mathrm{ng} / \mathrm{ml}$ basic fibroblast growth factor (FGF) (all from Invitrogen), and sodium pyruvate (Sigma).

After 6-9 d in cultures, spheres were collected, incubated in TripLE Express (Invitrogen) for $30-60 \mathrm{~min}$ at $37^{\circ} \mathrm{C}$, mechanically dissociated, and reseeded as single cells as described above. Experiments involving single cells or neurospheres exposed to LIF $(20 \mathrm{ng} / \mathrm{ml})$ were performed after four or more passages.

In each experiment, neurospheres were quantified in three to six wells and further classified according to their size ( $\geq 100 \mu \mathrm{m}$ diameter). Results are presented as mean \pm SEM neurospheres per well (i.e., per 5000 cells). Each experiment was repeated at least three times.

Statistics. Statistics were performed using the unpaired Student's $t$ test. Results are considered significant when the $p$ value is $<0.05$.

Online supplemental material. Supplemental Figure S1 illustrates the bioactivity of virally overexpressed LIF, assessed by phosphorylated Stat 3 (pStat3) staining. Supplemental Figure S2 shows expression of LIFR on various SVZ cell types. Supplemental Figure S3 offers a comparison between the in vitro and in vivo effects of LIF. The supplemental material is available at www.jneurosci.org.

\section{Results}

\section{LIF reduces neurogenesis in the $\mathrm{OB}$}

We focused our study on the SVZ, a well described system that generates neurons in the OB (for review, see Doetsch, 2003). The SVZ contains NSCs, the type B cells that express the astrocyte marker glial fibrillary acidic protein (GFAP) (Doetsch et al., 1999a; Garcia et al., 2004), the immediate progeny of which are the transit-amplifying, type $\mathrm{C}$ cells. Type $\mathrm{C}$ cells divide rapidly and generate neuroblasts, the type A cells, which migrate toward the OB (Doetsch et al., 1997).

To investigate the effects of overexpressing LIF on adult NSCs and neurogenesis, adult mice were injected in the lateral ventricle with an adenovirus encoding a secreted form of LIF (Ad:LIF) or $\beta$-galactosidase (Ad:LacZ) as a control (Zhu et al., 2001). Two weeks after virus inoculation, mice received daily intraperitoneal injections of BrdU for $7 \mathrm{~d}$ and were killed 1 week later ( 2 weeks after the first BrdU injection).

Adenoviruses efficiently infect ependymal cells when injected into the lateral ventricle (Doetsch et al., 1999a). Accordingly, we found that LIF or X-Gal (5-bromo-4-chloro-3-indolyl- $\beta$-Dgalactopyranoside) staining is confined to ependymal cells (data not shown). To confirm LIF activity in vivo, we performed pStat3 staining. Staining is abundant and localized to cell nuclei in Ad: LIF-treated animals, but not in Ad:LacZ-injected controls (supplemental Fig. S1, available at www.jneurosci.org as supplemental material). pStat3 staining intensity appears stronger in areas immediately adjacent to the ventricle, whereas it decreases farther away from the ventricle in a gradient-like pattern, suggesting maximal LIF activity in and around the SVZ.

In the $\mathrm{OB}, \mathrm{BrdU}+$ cells, either single labeled or colabeled with the mature neuronal marker NeuN, are mostly found in the subependymal and granule cell layers (Fig. 1), where newborn neurons are expected 1-2 weeks after being generated. Overexpression of LIF significantly reduces the number of both classes of cells in these anatomical layers, without affecting the percentage of newly generated neurons (Fig. 1). This suggests that LIF does not alter early neuronal differentiation or radial migration in the

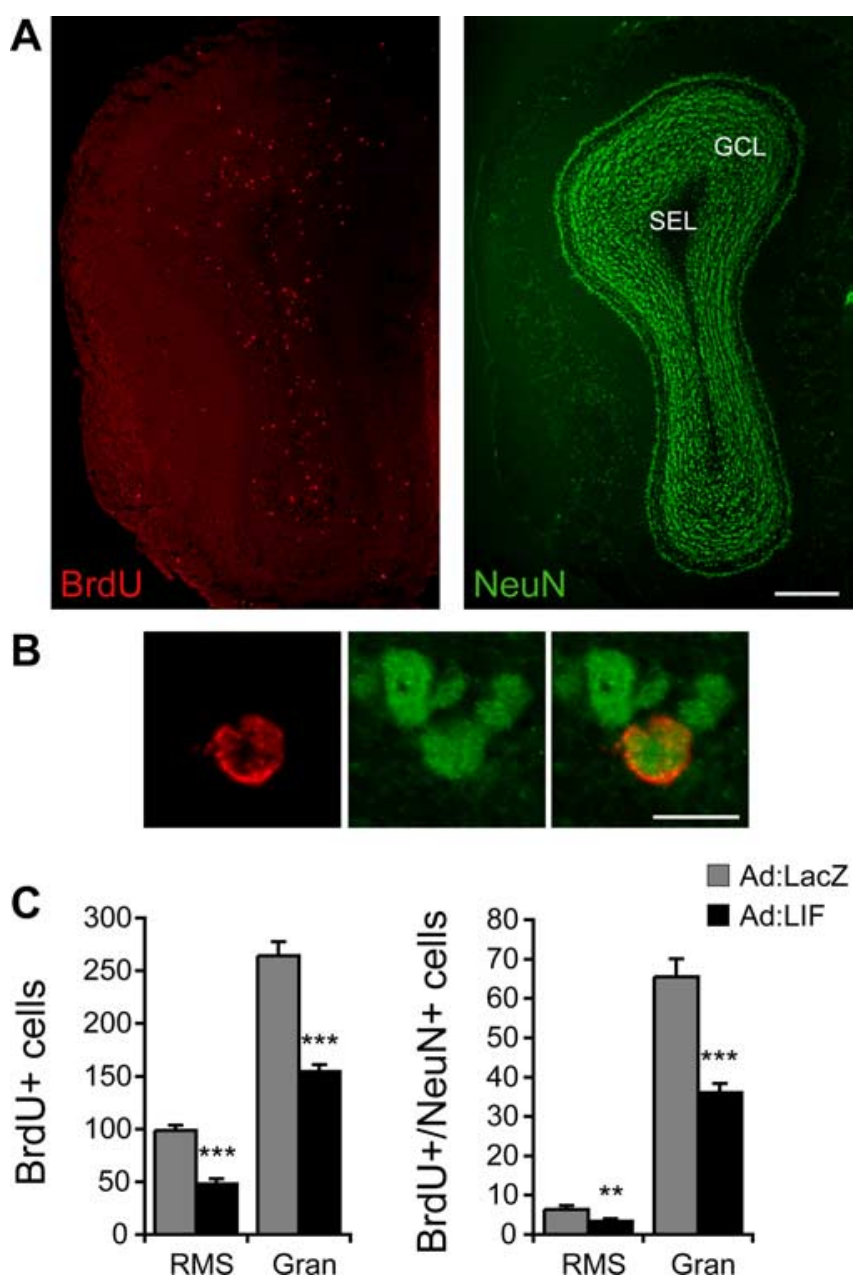

Figure 1. LIF reduces neurogenesis in the $\mathrm{OB} . \mathbf{A}$, Double staining for $\mathrm{BrdU}$ and the mature neuronal marker NeuN indicates that most BrdU + cells are found in the two deepest anatomical layers of the OB: the subependymal layer (SEL) and the granule cell layer (GCL). $\boldsymbol{B}, A n$ example of colocalization between BrdU and NeuN.C, The number of BrdU+ cells, as well as the number of newly generated neurons ( $\mathrm{BrdU}+/ \mathrm{NeuN}+$ ), is reduced by $41-51 \%$ in animals overexpressing LIF (Ad:LIF) compared with controls (Ad:LacZ), whereas the percentage of newly generated neurons is unchanged ( $6.3 \pm 0.8$ vs $7.2 \pm 0.9 \%$ and $25.0 \pm 1.4$ vs $23.5 \pm 1.4 \%$ in Ad:LacZ-vs Ad:LIF-treated animals in the SEL and GCL, respectively; $p=0.2)$. Data are mean \pm SEM of $n=5$ animals per group ( $2-3$ sections analyzed per animal). ${ }^{* *} p<0.01$ and ${ }^{* * *} p<$ 0.001 compared with Ad:LacZ-treated controls (Student's $t$ test). Scale bars: $\boldsymbol{A}, 300 \mu \mathrm{m} ; \boldsymbol{B}, 10$ $\mu \mathrm{m}$. RMS, Rostral migratory stream; Gran, granule cell layer.

$\mathrm{OB}$ proper, but rather reduces the number of newly generated cells coming from the SVZ that reach the OB. Thus, LIF may act "upstream" of the OB by altering SVZ cell fate.

\section{LIF impairs neuroblast formation in the SVZ}

We first checked whether cell proliferation in the SVZ is altered by LIF overexpression. In Ad:LIF-treated mice, the number of cells labeled with BrdU or with the endogenous cell-cycle marker Ki67 is only one-half of that in controls (Fig. 2), indicating that exogenous LIF strongly reduces SVZ cell proliferation. In contrast to the SVZ, other areas analyzed at the same anatomical level [i.e., the corpus callosum, striatum, and septum (hereafter referred to as periventricular areas)], as well as the cortex, all contain more Ki67+ or BrdU+ cells after LIF overexpression (Fig. 2).

In the SVZ, most of the proliferating cells correspond to neuroblasts (type A) and transit-amplifying cells (type C) (Doetsch et al., 1997). In Ad:LIF-treated animals, Dcx-expressing neuroblasts 
(Brown et al., 2003) are virtually absent (Fig. 3) (image analysis of Dcx staining in the SVZ: $6334.80 \pm 309.89$ vs $935.73 \pm$ 90.65 pixel $^{2}$ in Ad:LacZ-vs Ad:LIF-treated animals; $p<0.001$ ), and Mash1expressing type C cells (Fig. 3) (Parras et al., 2004) are greatly reduced (down $\sim 70 \% ; 57.80 \pm 4.39$ vs $16.80 \pm 1.61$ Mash1+ cells in Ad:LacZ- vs Ad:LIFtreated animals; $p<0.001$ ), indicating that LIF overexpression depletes the SVZ of cells in the neuronal lineage.

To better understand how LIF may be acting in the SVZ, we stained sections from naive animals with LIFR antibodies. Immunoreactivity is detected in all SVZ cell types (supplemental Fig. S2, available at www.jneurosci.org as supplemental material), including some GFAP+ astrocytes (type B cells) (Fig. 3). Thus, the previous data could be explained by several different mechanisms: LIF could directly (1) reduce the proliferation or (2) alter the fate of type A and C cells. It is also possible that the depletion of neuronal cells in the SVZ could be the consequence of (3) a direct effect of LIF on NSCs (type B), which would prevent the normal generation of NSC progeny, the type C and type A cells.

\section{LIF stimulates the proliferation of parenchymal glial progenitors in periventricular areas}

LIF may promote glial cell fate at the expense of the neuronal lineage in vivo, as it does in vitro (Bonni et al., 1997; Chang et al., 2004; Barnabe-Heider et al., 2005; He et al., 2005), which could explain the depletion of neuronal cells in the SVZ. Consistent with this hypothesis, phenotypic analysis in periventricular areas and the cortex of Ad:LIF-treated animals reveals a threefold to fivefold increase in BrdU+ cells expressing Olig2 or S100, two glial cell markers (Fig. 4). No newly generated $\mathrm{Dcx}+$ neurons are found, indicating that LIF does not stimulate neurogenesis in these areas (data not shown).

Interestingly, BrdU + cells appear to be distributed in a gradient-like pattern similar to the pStat3 staining, suggesting that LIF could induce SVZ cells to migrate out of the SVZ and invade periventricular areas, where they would adopt a glial phenotype. To check whether BrdU+ cells are derived from the SVZ or from local, parenchymal progenitors, we labeled SVZ cells and their progeny by injecting a GFPreplication-incompetent retrovirus in the SVZ before treatment with Ad:LIF or Ad: LacZ. Three weeks after virus injections, $\mathrm{GFP}+$ cells with the morphology and phenotype of immature neurons were seen in
A
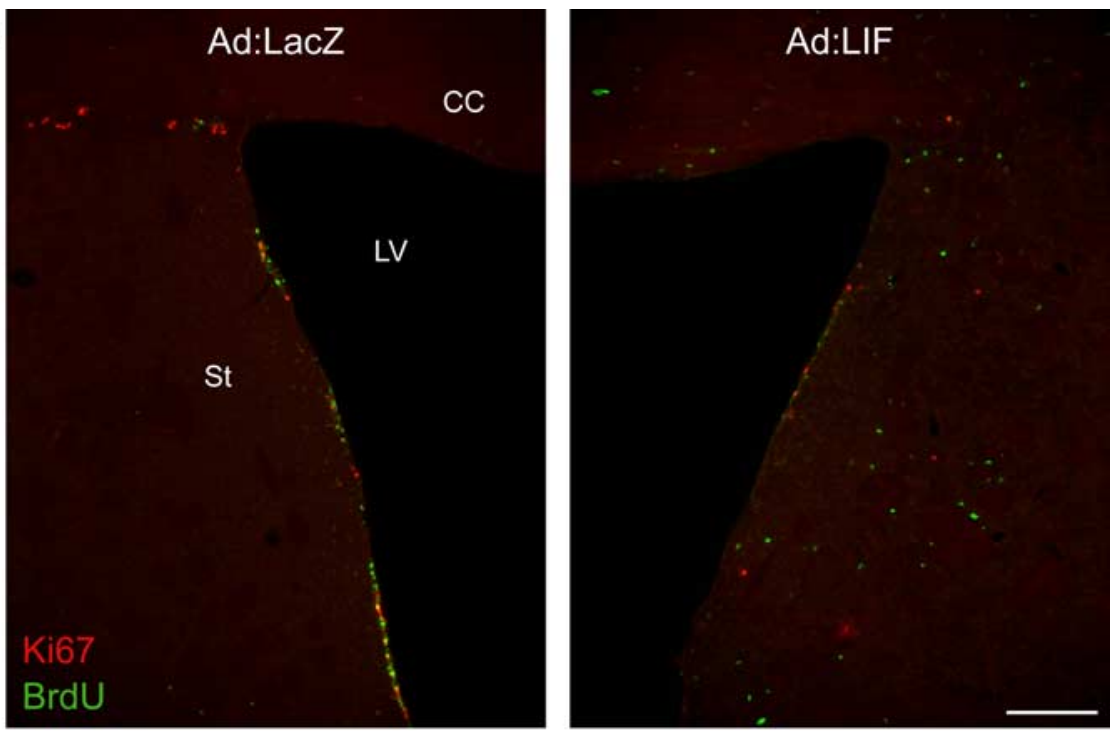

B
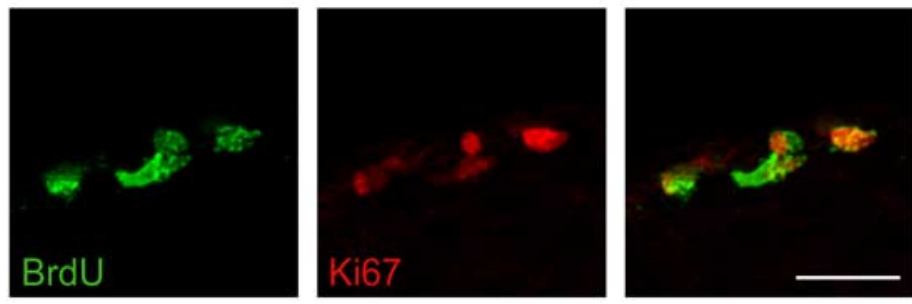

C
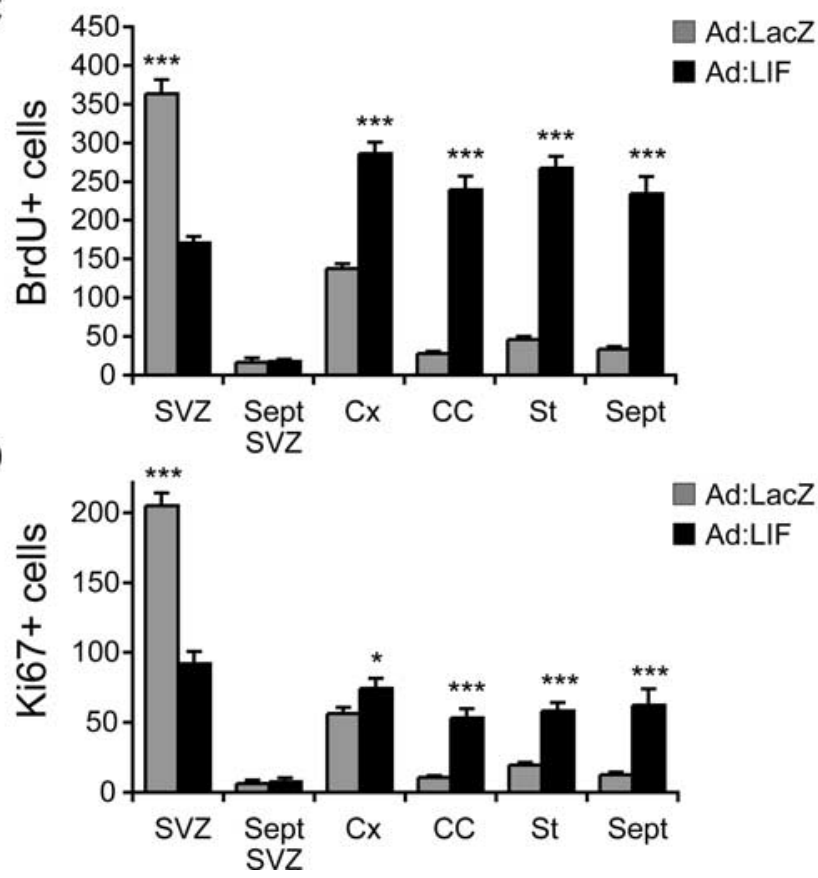

Ad:LacZ

Ad:LIF

Figure 2. LIF reduces cell proliferation in the SVZ. A, Double staining for BrdU and the endogenous cell-cycle marker Ki67 is shown on representative sections from a control animal (Ad:LaCZ) and an animal overexpressing LIF (Ad:LIF). CC, Corpus callosum; St, striatum; LV, lateral ventricle. Note the highly organized aspect of the SVZ in the control animal compared with treatment with Ad:LIF, in which fewer labeled cells are seen in the SVZ, but more in periventricular areas. $\boldsymbol{B}$, Higher magnification of SVZ cells double stained with BrdU and Ki67. C, D, Quantification of $\mathrm{BrdU}+(\boldsymbol{C})$ and Ki67 + (D) cells is shown for various brain regions at the anatomical level analyzed (between +0.3 and $+0.7 \mathrm{~mm}$ anterior to bregma). There is a $53-55 \%$ reduction in both classes of labeled cells in the SVZ of Ad:LIF-treated animals. In contrast, LIF overexpression triggers an increase in BrdU + as well as Ki67+ cells in periventricular areas [CC, St, and septum (Sept)] and the cortex (CX). Data are mean \pm SEM of $n=5$ animals per group ( $2-3$ sections analyzed per animal). ${ }^{*} p<0.05$ and ${ }^{* * *} p<0.001$ compared with Ad:LacZ-treated controls (Student's $t$ test). Sept SVZ, The ependyma lining the septal side of the lateral ventricle. Scale bars: $A, 150 \mu \mathrm{m} ; \boldsymbol{B}, 15 \mu \mathrm{m}$. 
A

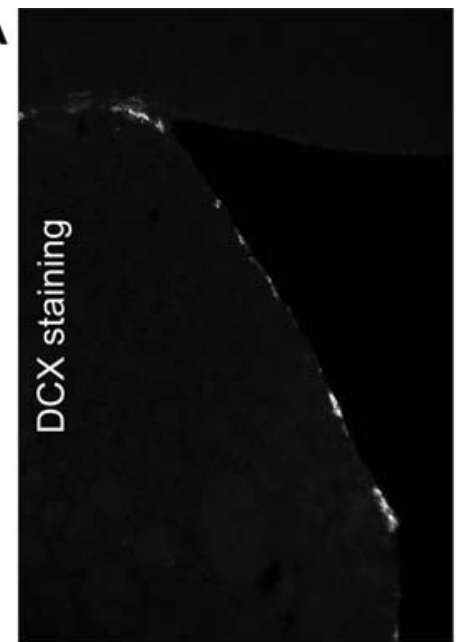

Ad:LacZ

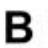

B

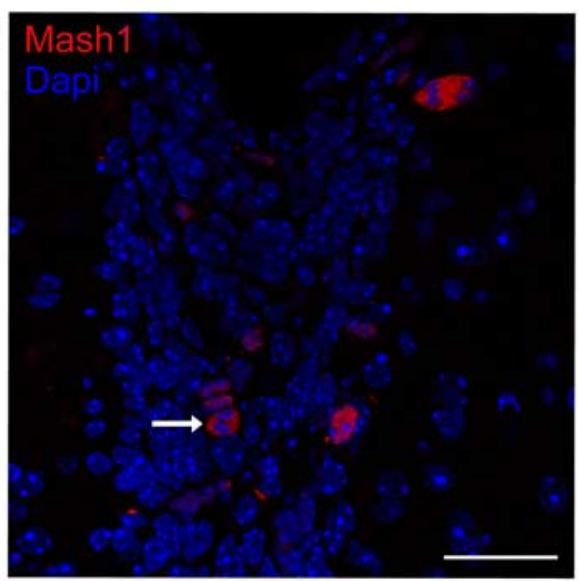

C

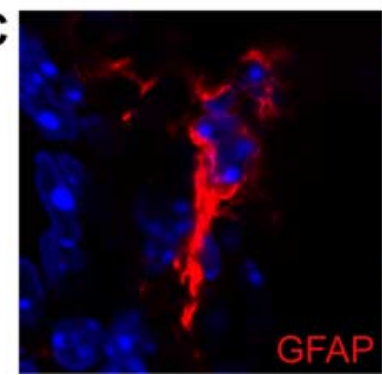

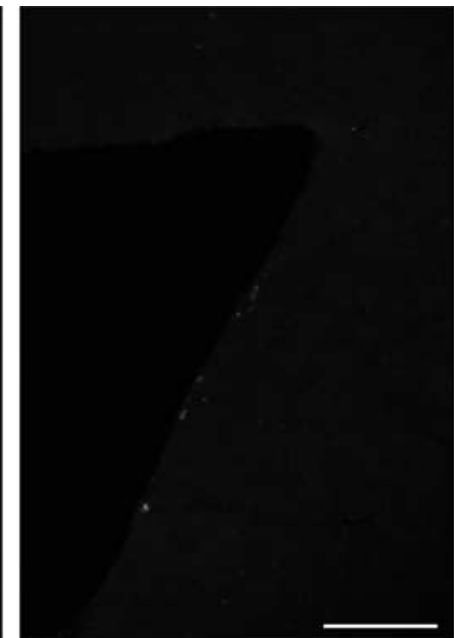

Ad:LIF
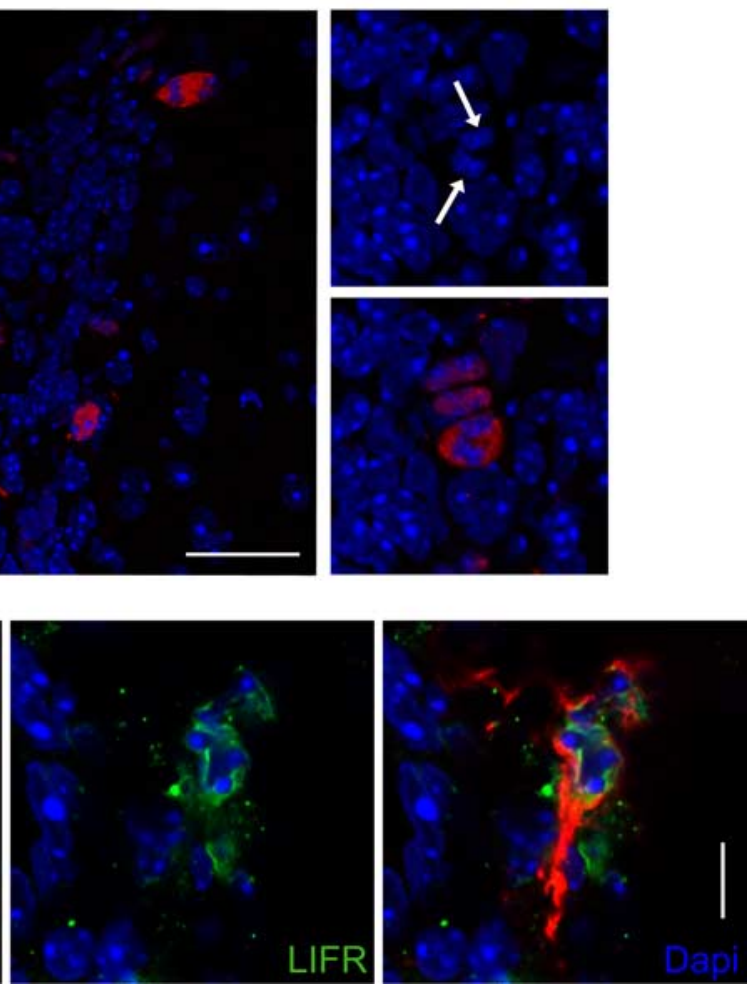

Figure 3. LIF reduces neuronal differentiation in the SVZ, and LIFR is expressed by some SVZ astrocytes. $A$, Dcx-expressing neuroblasts (type A cells) are greatly reduced in the SVZ of animals treated with Ad:LIF (see Results for image analysis data). $\boldsymbol{B}$, High magnification of SVZ cells stained with Mash1, a marker of transit-amplifying, type C cells. Note the mitosis (arrows and insets). C, LIFR immunoreactivity is detected on some GFAP-expressing astrocytes in the SVZ. Scale bars: $\boldsymbol{A}, 200 \mu \mathrm{m} ; \boldsymbol{B}, 30 \mu \mathrm{m}$ (insets, $15 \mu \mathrm{m}$ ); $C, 15 \mu \mathrm{m}$.

the OB of all animals (Fig. 4). However, no GFP+ cells were found in the striatum or septum of either group of mice (data not shown), suggesting that cells derived from the SVZ do not migrate normally in these areas and that LIF does not promote such ectopic migration. The corpus callosum in both Ad:LIF and Ad: LacZ mice contains some GFP + cells, likely because of the lesion induced at the time of virus injections. These results indicate that LIF-induced proliferation in periventricular areas, mostly glial in nature, originates from parenchymal, "activated" glial progenitors and not from SVZ-derived cells, which suggests a reactive gliosis that could be attributable to the proinflammatory effects of LIF (Sugiura et al., 2000; Kerr and Patterson, 2004). Thus, the reduction in SVZ progenitors and OB neurogenesis cannot be explained by an emigration or a change in cell fate of cells from the SVZ.

We also found that the number of $\mathrm{GFP}+$ cells is reduced by $\sim 60 \%$ in the $\mathrm{OB}$ of Ad:LIF-treated animals (Fig. 4) (image analysis of GFP staining in the OB: $1703.75 \pm 127.76$ vs $576.60 \pm 45.18$ pixel $^{2}$ in Ad:LacZ- vs Ad:LIF-treated animals; $p<0.001$ ), consistent with and confirming our previous observations with $\mathrm{BrdU}$ and NeuN. Given that the GFP retrovirus is likely infecting a majority of type $\mathrm{C}$ and A cells when injected into the SVZ, this result suggests that LIF is acting directly on these types of progenitors.

\section{LIF impairs the amplification of type C cells and stimulates the formation of SVZ astrocytes}

The above data indicate that the depletion of neuronal cells observed in the SVZ after LIF overexpression results from a deregulation of cell lineage homeostasis that is spatially restricted to the SVZ. It is possible that LIF impairs the amplification of type C cells and the transition to type A cells. We studied self-renewal/cell cycle kinetics in the SVZ by analyzing Ki67/BrdU double staining using animals that were killed 1 week after the last BrdU injection. This 1 week survival allows most migrating $\mathrm{BrdU}+$ neuroblasts to be cleared from the SVZ and reach the OB. Hence, BrdU+ cells that are left in the SVZ and that coexpress Ki67 correspond to self-renewing cells or to cells with a long cell cycle $(>1$ week; i.e., type $\mathrm{C}$ or type $\mathrm{B}$ cells). Given that the NSC fraction (B cells) is estimated to represent only $0.2-0.4 \%$ of the SVZ, and that $C$ cells reside for $\sim 2$ weeks in the SVZ (Morshead et al., 1998), the majority of the Ki67+/BrdU+ cells in our experiment likely correspond to self-renewing type $\mathrm{C}$ cells. LIF reduces the number of $\mathrm{Ki} 67+/ \mathrm{BrdU}+$ cells by $\sim 50 \%$ (33.3 \pm 2.0 vs $17.5 \pm 2.2 \mathrm{Ki} 67+/ \mathrm{BrdU}+$ cells in $\mathrm{Ad}$ : LacZ- vs Ad:LIF-treated animals; $p<$ 0.001 ), consistent with the reduction of $\mathrm{C}$ cells observed with Mash1. Because LIF also reduces proliferation, an index of self-renewal was calculated by dividing the number of self-renewing cells $(\mathrm{BrdU}+/ \mathrm{Ki} 67+)$ by the total number of BrdU+ cells. This ratio is significantly decreased in the dorsolateral corner of the SVZ $(14.6 \pm 2.1$ vs $8.9 \pm 1.7 \%$ in Ad:LacZ- vs Ad:LIF-treated animals; $p=0.02)$, suggesting that LIF overexpression reduces type C cell self-renewal.

It is also possible that LIF could act directly on NSCs, as suggested by the localization of LIFR on SVZ GFAP + cells (Fig. 3), and impair type $\mathrm{C}$ cell production. Interestingly, we found that the SVZ of Ad:LIF-treated animals contains fivefold more Olig $2+$ or $\mathrm{S} 100+$ cells colabeled with BrdU compared with con- 
trols (Fig. 4), indicating that the depletion of neuronal cells is counterbalanced by an increased formation of glial cells. Interestingly, Olig2 expression has recently been identified in a subset of type B cells and colocalizes with S100 in some SVZ cells (Menn et al., 2006). Most noteworthy, many $\mathrm{S} 100+/ \mathrm{BrdU}+$ cells in the SVZ of Ad:LIF-treated animals also express GFAP (Fig. 4), a marker of neural stem type B cells (Doetsch et al., 1999a; Garcia et al., 2004). Thus, LIF appears to promote the proliferation or formation of SVZ astrocytes, at the expense of other SVZ cell types. These SVZ astrocytes may correspond to differentiated astrocytes that lose their stem cell potential, which would be consistent with the well known astrocytepromoting effect of LIF in vitro, or to putative NSCs. Either effect would decrease the formation of type $\mathrm{C}$ and type A cells and reduce subsequent $\mathrm{OB}$ neurogenesis.

\section{Infusion of LIF after AraC impairs SVZ regeneration in vivo}

To address the possibility that LIF directly affects NSCs in vivo, we examined how the SVZ regenerates in the presence of LIF, after infusion of the antimitotic drug AraC (Doetsch et al., 1999b). AraC kills actively proliferating SVZ cells, type A and C cells, but spares type B cells (NSCs), which proliferate after AraC removal and sequentially regenerate type $\mathrm{C}$ and type A cells (Doetsch et al., 1999b). AraC was infused in the lateral ventricle for $6 \mathrm{~d}$ and was followed by infusion of recombinant LIF protein or PBS as a control. Mice were killed 1-2 $\mathrm{h}$ after a single BrdU injection 1, 3, or $7 \mathrm{~d}$ after AraC removal/LIF infusion, when type $B$, type $C$, and type A cells reappear and massively proliferate, respectively (Doetsch et al., 1999b).

At all time points examined after AraC removal, SVZ cell proliferation (BrdU staining) is reduced by $\sim 50 \%$ in animals infused with LIF compared with controls (Fig. 5). As expected, the number of BrdU + cells increases in controls between 1 and $3 \mathrm{~d}$ of regeneration, reflecting the reappearance of type C cells from NSCs (Doetsch et al., 1999b). However, no such increase is apparent in LIF-treated animals (Fig. 5), suggesting that type $\mathrm{C}$ cells do not fully reappear. Indeed, proliferating $\mathrm{C}$ cells, identified by coexpression of BrdU and the EGFR (Doetsch et al., 2002) (Fig. $5)$, are strongly reduced $(>70 \%)$ in LIFtreated animals $(71.67 \pm 4.65$ vs $21.33 \pm$ $3.52 \mathrm{BrdU}+/ \mathrm{EGFR}+$ cells in PBS-infused controls vs LIF-treated animals; $p<$ 0.001). Furthermore, BrdU+/EGFR+ cells account for only $50 \%$ of the prolifer-
A
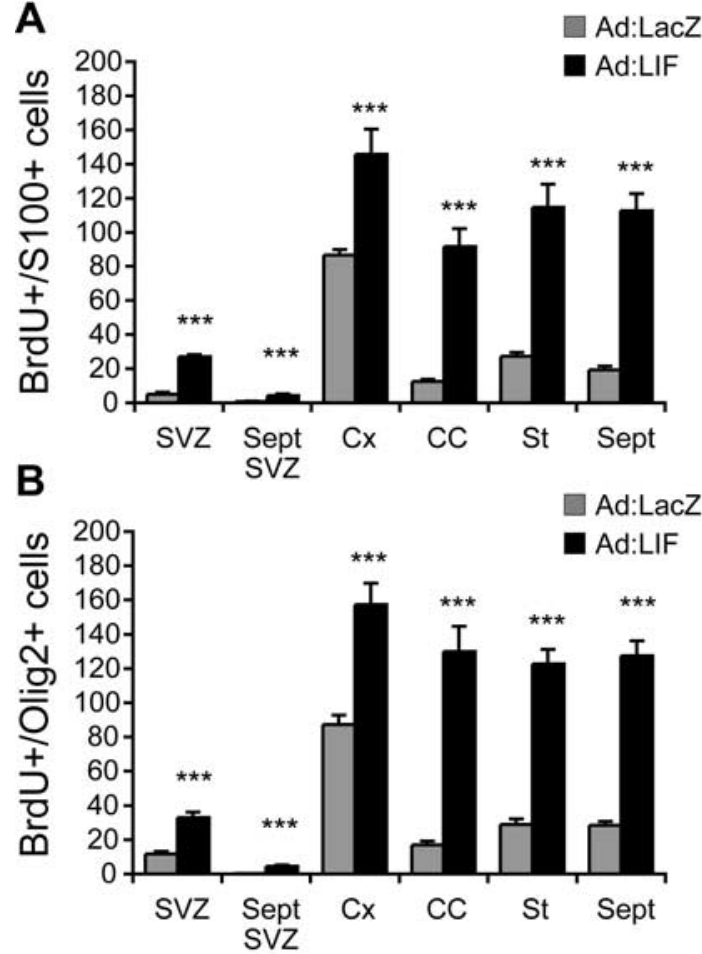

D

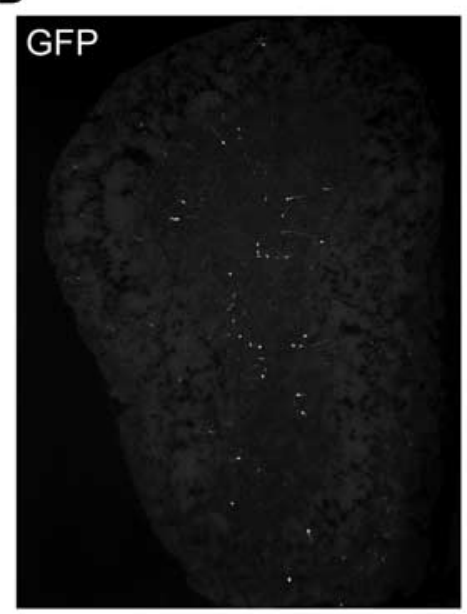

Ad:LacZ

E

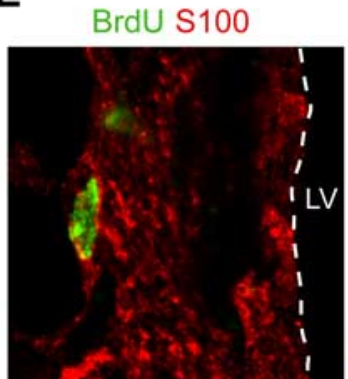

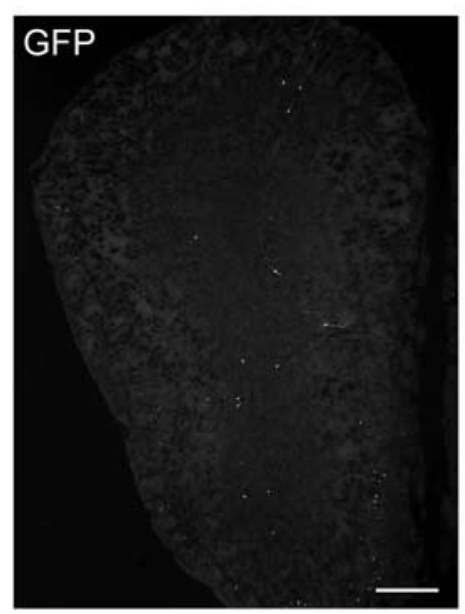

Ad:LIF

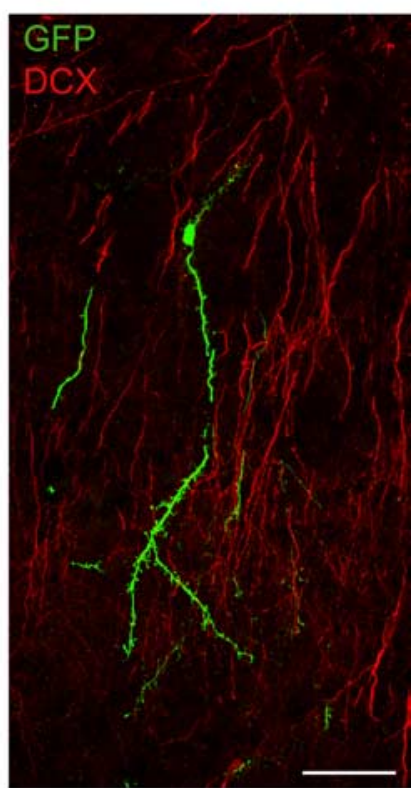


A

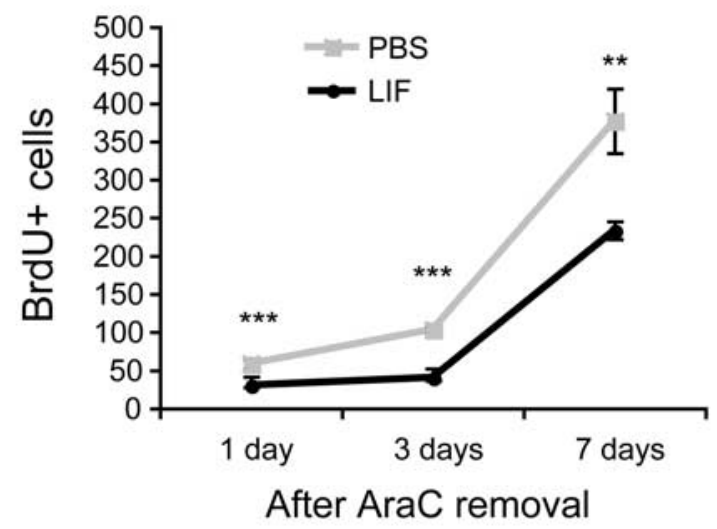

B

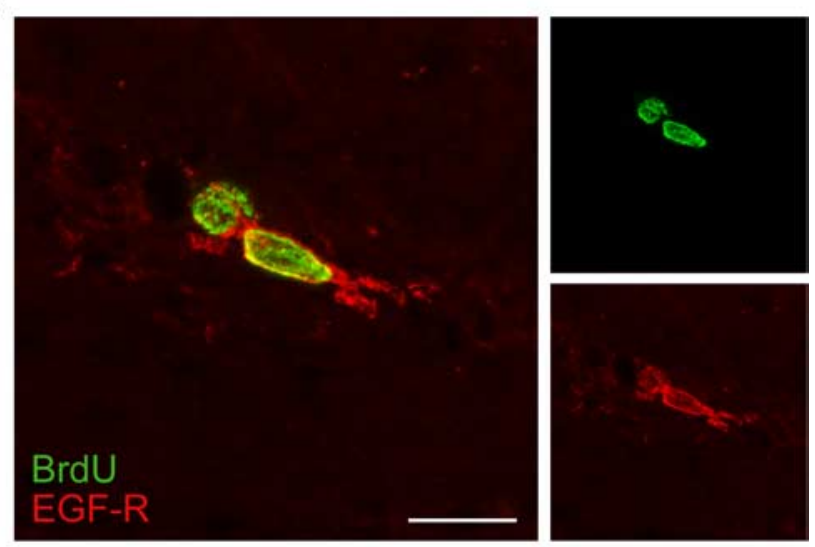

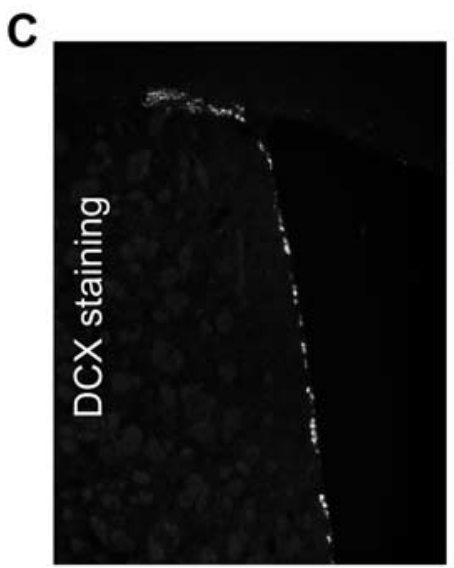

PBS

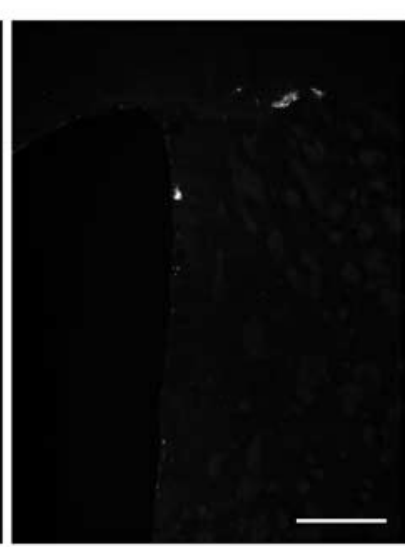

LIF
Figure 5. Infusion of LIF after a $6 \mathrm{~d}$ AraC treatment impairs SVZ regeneration in vivo by acting directly on NSCS. A, Quantification of BrdU+ cells in the SVZ indicates that LIF reduces the number of BrdU + cells at 1, 3, and $7 \mathrm{~d}$ after AraC removal. $\boldsymbol{B}$, High magnification of SVZ cells double stained for BrdU and EGFR, a marker of transit-amplifying cells (type C). C, Representative sections stained with Dcx (a marker of neuroblasts) $7 \mathrm{~d}$ after AraC removal/LIF infusion. LIF strongly impairs the reappearance of neuroblasts (see Results for image analysis data). Data are mean \pm SEM of $n=3$ animals per group ( $2-3$ sections analyzed per animal). ${ }^{* *} p<0.01$ and ${ }^{* * *} p<0.001$ compared with PBS-infused controls (Student's $t$ test). Scale bars: $\boldsymbol{B}, 15 \mu \mathrm{m}$ (inset, $30 \mu \mathrm{m}$ ); $\boldsymbol{C}, 200 \mu \mathrm{m}$.

$\leftarrow$

(Figurelegend continued.) $n=5$ animals per group ( $2-3$ sections analyzed per animal). ${ }^{* * *} p<$ 0.001 compared with Ad:LacZ-treated controls (Student's t test). Sept SVZ, Ependyma lining the septal side of the lateral ventricle; $C x$, cortex; CC, corpus callosum; LV, lateral ventricle; St, striatum; Sept, septum. Scale bars: $\boldsymbol{C}, 50 \mu \mathrm{m} ; \boldsymbol{D}, 300 \mu \mathrm{m} ; \boldsymbol{E}, 10 \mu \mathrm{m}$. ating cells in animals infused with LIF, whereas their proportion reaches $70 \%$ in controls $(p=0.005)$, as reported previously (Doetsch et al., 1999b). Thus, these results indicate a lack of or delay in the generation of type C cells from NSCs when the SVZ regenerates in the presence of LIF. Some neuroblasts do reappear $7 \mathrm{~d}$ after AraC removal/LIF infusion, but to a much lower extent than in control (Fig. 5) (image analysis of Dcx staining in the SVZ: $4383.22 \pm 595.84$ vs $1116.22 \pm 92.10$ pixel $^{2}$ in PBS vs LIFinfused animals; $p<0.001$ ).

Altogether, our results indicate that LIF acts directly on NSCs in vivo and prevents the normal generation of NSCs progeny during the regeneration process.

\section{LIF promotes adult NSC self-renewal in vivo and in vitro}

LIF could prevent the emergence of more differentiated progeny as a result of promoting symmetric cell division and self-renewal of adult NSCs in vivo. To analyze the effects of LIF on NSC selfrenewal, we first used the neurosphere assay in vitro. Adult SVZderived neurospheres were grown in proliferative conditions for $6 \mathrm{~d}$ in vitro (DIV) and exposed to LIF for the last 2 DIV, which does not change the number or size of the neurospheres (supplemental Fig. 3, available at www.jneurosci.org as supplemental material). Neurospheres were then dissociated, and single cells were replated in normal proliferative conditions without LIF for another 7-9 DIV to score the number of secondary neurospheres generated. The transient incubation in LIF during the last 2 DIV increases secondary sphere formation by nearly $70 \%$ (Fig. 6). These neurospheres could be passaged and were multipotent (data not shown), suggesting that LIF promotes the self-renewal of sphere-forming cells with NSC characteristics in vitro.

To determine whether LIF also stimulates the self-renewal of NSCs in vivo, we made use of the fact that stem cells retain exogenous thymidine analogs after long-term survival (Morshead et al., 1994, 1998; Doetsch et al., 1999a). We further refined this method by using a double nucleoside labeling strategy to monitor the proportion of long-term, label-retaining cells that reenter the cell cycle (Maslov et al., 2004). In this experiment, adult mice were given nucleoside analogs in their drinking water, starting with a 2 week treatment with IdU, followed by 1 week without label and by an Ad:LIF or Ad:LacZ injection. Mice were then given CldU for another 2 weeks, followed by 1 week without label before they were killed, a total of 4 weeks after the end of IdU administration. In this experiment, the SVZ should contain longterm, label-retaining cells that are IdU+, some of which become quiescent, whereas others are still proliferating and likely correspond to self-renewing NSCs, which can thus be identified by the incorporation of both markers, IdU and CldU.

Ad:LIF treatment increases the number of IdU + cells (by $\sim 30 \%$ ) (Fig. 6), indicating that LIF promotes the retention of long-term, label-retaining cells in the SVZ. Importantly, LIF also produces a twofold increase in the number of cells double labeled with IdU and CldU and increases the proportion of self-renewing cells (IdU+/CldU + ) among the total number of long-term, label-retaining cells (IdU+) (Fig. 6). These data indicate that LIF promotes the formation of long-term, label-retaining cells that reenter the cell cycle, which are candidate NSCs. Although it is possible that some IdU+/CldU + cells correspond to type C cells, their contribution in our experiment is likely minimal, because we find that LIF strongly reduces the number of $C$ cells. Furthermore, previous studies found that the only SVZ cells labeled 1 month after nucleoside administration are the type B cells (Doetsch et al., 1999a). Thus, the increase in IdU+/CldU+ cells likely reflects a greater number of NSCs that reenter the cell cycle, 
suggesting that LIF promotes the selfrenewal of proliferating NSCs in vivo.

In conclusion, our results strongly suggest that LIF expands the pool of adult NSCs by promoting their self-renewal, thereby preventing the emergence of more differentiated progeny, both in vivo and in vitro.

\section{Infusion of LIF before AraC promotes SVZ regeneration}

Therapeutic strategies for brain repair include the stimulation of endogenous progenitors to promote cell replacement. Thus, it is of interest to determine whether the increased number of NSCs induced by LIF treatment in vivo may be useful in regeneration of cell populations. Given the strong correlation between the effects of LIF on sphere formation in vitro and on the early phases of SVZ regeneration in vivo (supplemental Fig. 3, available at www. jneurosci.org as supplemental material), and because LIF exposure for the last 2 DIV strongly stimulates secondary sphere formation, we asked whether a previous, short-term exposure to LIF in vivo in a normal SVZ environment, before infusing AraC, leads to a stimulation of the regenerative process (the equivalent of an increased secondary sphere formation).

We tested this by infusing LIF or PBS for $3 \mathrm{~d}$ in the lateral ventricle before a $6 \mathrm{~d}$ AraC infusion. Animals received a single BrdU injection $1 \mathrm{~h}$ before they were killed, $3 \mathrm{~d}$ after AraC removal. Remarkably, the number of BrdU+ or Ki67 + cells is significantly increased in the SVZ of animals treated with LIF before AraC, as is the number of proliferating EGFR+ type C cells (Table 1). In contrast, a 3 d infusion of EGF instead of LIF before AraC infusion has no effect on subsequent SVZ regeneration (Table 1), indicating that the effects of LIF are specific. Because EGF acts primarily on type C but not type B (NSCs) cells (Doetsch et al., 2002), this suggests that LIF-mediated acceleration of SVZ regeneration results from an effect on NSCs. Furthermore, we find that SVZ cell proliferation, although strongly decreased by a $3 \mathrm{~d}$ LIF infusion, quickly returns to nearcontrol levels as soon as $1 \mathrm{~d}$ after LIF removal (data not shown), making it unlikely that type $\mathrm{C}$ cells could be protected from AraC-induced degeneration.

Thus, our data indicate that LIF infusion, before inducing SVZ degeneration, accelerates the subsequent regenerative process, possibly as a result of expanding the pool of NSCs through the promotion of self-renewing divisions. This could be attributable to a direct effect of LIF on NSCs or, alternatively, could be mediated indirectly, through cells activated by LIF outside the SVZ.

A
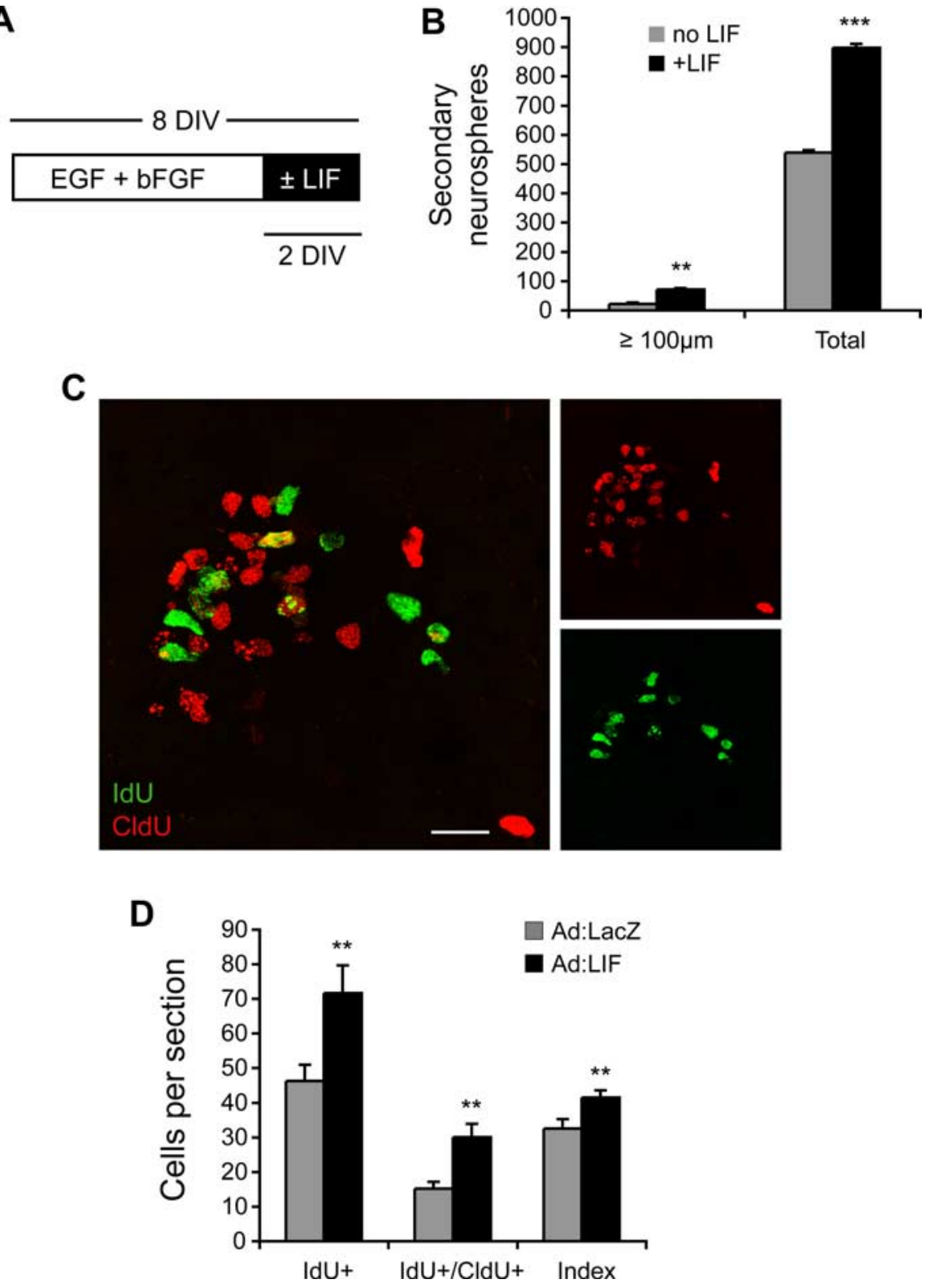

Figure 6. LIF stimulates the self-renewal of sphere-forming cells in vitro, as well as the renewal of long-term, label-retaining cells in vivo. $\boldsymbol{A}$, Schematic representation of the protocol used in vitro. Growing neurospheres were incubated with $\operatorname{LIF}(20 \mathrm{ng} / \mathrm{ml})$ during the last 2 DIV. These neurospheres were then dissociated to assess secondary neurosphere formation. $\boldsymbol{B}$, Quantification of secondary spheres. Neurospheres pretreated with LIF during the last 2 DIV (from 6 to 8 DIV) yield 70\% more secondary neurospheres compared with neurospheres that were not exposed to LIF. This increase is observed on the total population of spheres as well as on larger neurospheres ( $\geq 100 \mu \mathrm{m}$ diameter). C, Pictures illustrate an example of the IdU and CIdU double staining. D, LIF induces a $30 \%$ increase in the number of long-term, label-retaining cells (IdU+), as well as a twofold increase in the number of long-term, label-retaining cells that reenter the cell cycle (IdU +/CldU +). LIF also increases the proportion of IdU $+/$ CldU + cells among the total IdU + cells (Index; i.e., the proportion of self-renewing, long-term, label-retaining cells that reenter the cell cycle). Data are mean \pm SEM of $n=3$ animals per group (3 sections analyzed per animal) or $n=3-6$ wells per condition (independent experiments were performed at least 3 times and gave similar results). ${ }^{* *} p<0.01$ and ${ }^{* * *} p<0.001$ compared with Ad:LacZ-treated control animals or spheres incubated without LIF (Student's $t$ test). Scale bar: C, $30 \mu \mathrm{m}$ (inset, $60 \mu \mathrm{m}$ ).

\section{Discussion}

The adult SVZ, where new OB neurons are born, contains rapidly dividing progenitors, neuroblasts and transit-amplifying cells, the type A and type $\mathrm{C}$ cells, respectively. We find that exogenous LIF strongly reduces SVZ cell proliferation and subsequent neurogenesis in the adult $\mathrm{OB}$. At the same time, we find that LIF promotes the self-renewal of NSCs, ultimately expanding this 
Table 1. Infusion of LIF for $3 \mathrm{~d}$ before a $6 \mathrm{~d}$ AraC treatment promotes subsequent SVZ regeneration, whereas EGF instead of LIF has no effect

\begin{tabular}{lcrc}
\hline & LIF before AraC & PBS before AraC & EGF before AraC \\
\hline BrdU+ cells & $82.61 \pm 4.86^{*}$ & $60.0 \pm 3.77$ & $55.83 \pm 4.10^{\dagger}$ \\
Ki67+ cells & $144.50 \pm 3.33^{* *}$ & $119.11 \pm 5.87$ & $109.83 \pm 8.01^{\text {t† }}$ \\
BrdU+/EGFR+ cells & $49.22 \pm 2.78^{*}$ & $32.67 \pm 3.57$ & $\mathrm{ND}$ \\
\hline
\end{tabular}

In contrast, infusion of EGF before AraC has no effect on subsequent SVZ regeneration. Cell counts were performed $3 \mathrm{~d}$ after AraC removal. Data are mean \pm SEM of $n=3$ animals per group ( 3 sections analyzed per animal). ND, Not determined. ${ }^{*} p=0.001$ and ${ }^{* *} p=0.003$ compared with PBS-infused controls (Student's $t$ test). ${ }^{\dagger} p=0.294$ and ${ }^{+t} p=0.255$ compared with vehicle-infused controls (data not shown, results similar to PBS-infused controls).

discrete cell population, which normally represents only $0.2-0.4 \%$ of the SVZ cells. Thus, chronic overexpression of LIF in vivo maintains NSCs in a loop of symmetric/self-renewing divisions, preventing the emergence of more differentiated progeny. A similar deregulation of the SVZ cell lineage in vivo has been described after application of exogenous EGF, which also reduces neurogenesis but does so by acting on transit-amplifying cells (Doetsch et al., 2002).

Our results are consistent with and expand on recent studies examining the in vitro effects of LIF on embryonic neurospheres (Pitman et al., 2004; Bonaguidi et al., 2005), in which LIF promotes secondary sphere formation. Although LIF induces a marker of astrocyte differentiation (GFAP), the morphology and phenotype of these LIF-treated cells is distinct from astrocytes generated in the presence of bone morphogenic proteins (BMPs), another gliogenic cytokine family (Bonaguidi et al., 2005). Major differences include bipolar/elongated/radial morphology in LIF but a stellate morphology in BMPs and expression of radial glial markers such as vimentin in LIF but not in BMPs (Bonaguidi et al., 2005). Furthermore, proliferation continues in the presence of LIF but is strongly inhibited in BMPs, and neurospheres can be obtained very efficiently from LIF-generated astrocytes, but not from astrocytes generated in BMPs (Bonaguidi et al., 2005). Interestingly, the bipolar/elongated/radial morphology of LIFgenerated astrocytes is reminiscent of the morphology described in vivo for adult GFAP-expressing NSCs (Garcia et al., 2004) and is consistent with our findings (Fig. 4). Overexpressing BMP in vivo prevents cell proliferation and neurogenesis in the adult SVZ (Lim et al., 2000), similar to our findings with LIF. In the hippocampus, overexpression of BMPs reduces proliferation and downregulates the expression of neural progenitor markers in GFAP + cells (Bonaguidi et al., 2005). Thus, BMPs induce differentiation of GFAP-expressing NSCs into astrocytes that lose their stem cell potential, whereas LIF maintains their stem cell characteristics. Despite our findings that LIF acts on NSCs during SVZ regeneration and that LIFR is expressed on some GFAP+ cells, we cannot exclude the possibility that LIF promotes GFAP expression in a subset of type $\mathrm{C}$ cells, which may dedifferentiate and acquire NSC characteristics, similar to the effects of exogenous EGF treatment (Doetsch et al., 2002). Indeed, EGFR signaling synergizes with LIF to induce astrocyte differentiation (Viti et al., 2003), and we also find colocalization of EGFR with LIFR (supplemental Fig. 2, available at www.jneurosci.org as supplemental material).

In contrast to the effects of LIF described in our study, exogenous CNTF stimulates SVZ cell proliferation (Shimazaki et al., 2001) and neurogenesis in the adult brain (Emsley and Hagg, 2003; Kokoeva et al., 2005), suggesting that LIF and CNTF have different biological effects. Indeed, slightly more neurospheres were derived from the ependyma of adult mice infused with CNTF (Shimazaki et al., 2001), whereas we derived fewer neurospheres from mice treated with Ad:LIF (our unpublished results).
Given that up to $70 \%$ of neurospheres come from type C cells (Doetsch et al., 2002), this suggests that CNTF may increase the number of type $\mathrm{C}$ cells, whereas we find that LIF decreases it. The dose of CNTF used may also be an issue. For example, a high dose of CNTF results in the promotion of neurogenesis in the hypothalamus [656 ng/d (Kokoeva et al., 2005)], whereas we used a much lower dose of LIF (60-120 ng/d). In another example, the dose of EGF has been reported to differentially affect type C cell phenotype (Doetsch et al., 2002). Discrepancies also exist in vitro, because some reports indicate that CNTF or LIF do not affect neurosphere formation (Shimazaki et al., 2001; Gregg and Weiss, 2005), whereas others find that they do (Pitman et al., 2004; present study; our unpublished results). Nevertheless, CNTF exposure for the last 4 DIV increases secondary neurosphere formation (Shimazaki et al., 2001), similar to the effect of LIF (present study). Whether LIF and CNTF have similar effects on adult NSCs in vivo remains to be determined.

Endogenous LIFR signaling promotes the maintenance of embryonic and adult NSCs in vivo and in vitro (Shimazaki et al., 2001; Pitman et al., 2004), and intracerebroventricular injection of anti-CNTF antibodies decreases adult neurogenesis (Emsley and Hagg, 2003). We did not address the role of endogenous LIF in this study, but LIF expression is generally very low under physiological conditions. Thus, LIF knock-out mice display no difference in olfactory precursor cell proliferation unless injury is performed, at which point LIF is required for proliferation (Bauer et al., 2003). Interestingly, brain injuries are potent inducers of LIF expression and also increase SVZ or hippocampal cell proliferation, suggesting that LIF may be a key signaling molecule that triggers progenitor cell recruitment after injury. Endogenous LIF promotes cell proliferation after spinal cord injury, which is further potentiated by exogenous LIF treatment (Kerr and Patterson, 2004). We demonstrate here that exogenous LIF accelerates SVZ regeneration when infused before AraC, possibly by promoting NSC self-renewal, which suggests that LIF could be used to stimulate brain repair after injury.

In this context, the effects of chronic versus acute LIF treatment are important to consider. Indeed, chronic exposure to LIF is not physiological, because LIF expression after injury is rapid and transient. Our data emphasize that downregulation of LIF is necessary to end the stimulation of NSC self-renewal and allow the harnessing of the regenerative potential of NSCs. The transient expression of LIF observed after injury may thus trigger a period of increased NSC self-renewal, which likely constitutes the first step toward regeneration. Our data also suggest a model for the development of successful therapeutic regenerative strategies from endogenous NSCs, whereby brain repair may be achieved with critically timed exposure to factors that stimulate NSC selfrenewal first, followed by exposure to other factors that promote survival, migration, and differentiation of NSC progeny.

Finally, it is interesting to note that our results are reminiscent of LIF action on mouse ES cells, suggesting a continuum from ES cells to adult NSCs. This view is supported by recent findings showing that mouse ES cells plated in minimal conditions default to a neural fate and transform into LIF-dependent primordial NSCs, which in turn generate FGF2-dependent definitive NSCs (Smukler et al., 2006). In those experiments, LIF appears to maintain a population of primordial NSCs in an undifferentiated state by preventing additional neural differentiation of the ES cells (Smukler et al., 2006). LIF-dependent, primordial NSCs similar to those derived from ES cells have also been obtained from embryonic day 5.5 mouse neuroectoderm (Hitoshi et al., 2004), suggesting that the continuum from ES cells to NSCs described in 
vitro may also exist in vivo. Together with these studies, our data show that LIF exerts a similar range of actions from ES cells to adult NSCs and suggest that common mechanisms participate in the maintenance of these various types of stem cells.

\section{References}

Arvidsson A, Collin T, Kirik D, Kokaia Z, Lindvall O (2002) Neuronal replacement from endogenous precursors in the adult brain after stroke. Nat Med 8:963-970.

Banner LR, Patterson PH (1994) Major changes in the expression of the mRNAs for cholinergic differentiation factor/leukemia inhibitory factor and its receptor after injury to adult peripheral nerves and ganglia. Proc Natl Acad Sci USA 91:7109-7113.

Banner LR, Moayeri NN, Patterson PH (1997) Leukemia inhibitory factor is expressed in astrocytes following cortical brain injury. Exp Neurol 147:1-9.

Barnabe-Heider F, Wasylnka JA, Fernandes KJ, Porsche C, Sendtner M, Kaplan DR, Miller FD (2005) Evidence that embryonic neurons regulate the onset of cortical gliogenesis via cardiotrophin-1. Neuron 48:253-265.

Bauer S, Patterson PH (2005) The cell cycle-apoptosis connection revisited in the adult brain. J Cell Biol 171:641-650.

Bauer S, Rasika S, Han J, Mauduit C, Raccurt M, Morel G, Jourdan F, Benahmed M, Moyse E, Patterson PH (2003) Leukemia inhibitory factor is a key signal for injury-induced neurogenesis in the adult mouse olfactory epithelium. J Neurosci 23:1792-1803.

Bonaguidi MA, McGuire T, Hu M, Kan L, Samanta J, Kessler JA (2005) LIF and BMP signaling generate separate and discrete types of GFAPexpressing cells. Development 132:5503-5514.

Bonni A, Sun Y, Nadal-Vicens M, Bhatt A, Frank DA, Rozovsky I, Stahl N, Yancopoulos GD, Greenberg ME (1997) Regulation of gliogenesis in the central nervous system by the JAK-STAT signaling pathway. Science 278:477-483.

Brown JP, Couillard-Despres S, Cooper-Kuhn CM, Winkler J, Aigner L, Kuhn HG (2003) Transient expression of doublecortin during adult neurogenesis. J Comp Neurol 467:1-10.

Chang MY, Park CH, Son H, Lee YS, Lee SH (2004) Developmental stagedependent self-regulation of embryonic cortical precursor cell survival and differentiation by leukemia inhibitory factor. Cell Death Differ 11:985-996.

Charrier C, Coronas V, Fombonne J, Roger M, Jean A, Krantic S, Moyse E (2006) Characterization of neural stem cells in the dorsal vagal complex of adult rat by in vivo proliferation labeling and in vitro neurosphere assay. Neuroscience 138:5-16.

Chojnacki A, Shimazaki T, Gregg C, Weinmaster G, Weiss S (2003) Glycoprotein 130 signaling regulates Notch 1 expression and activation in the self-renewal of mammalian forebrain neural stem cells. J Neurosci 23:1730-1741.

Corness J, Shi TJ, Xu ZQ, Brulet P, Hokfelt T (1996) Influence of leukemia inhibitory factor on galanin/GMAP and neuropeptide $\mathrm{Y}$ expression in mouse primary sensory neurons after axotomy. Exp Brain Res 112:79-88.

Doetsch F (2003) The glial identity of neural stem cells. Nat Neurosci 6:1127-1134

Doetsch F, Garcia-Verdugo JM, Alvarez-Buylla A (1997) Cellular composition and three-dimensional organization of the subventricular germinal zone in the adult mammalian brain. J Neurosci 17:5046-5061.

Doetsch F, Caille I, Lim DA, Garcia-Verdugo JM, Alvarez-Buylla A (1999a) Subventricular zone astrocytes are neural stem cells in the adult mammalian brain. Cell 97:703-716.

Doetsch F, Garcia-Verdugo JM, Alvarez-Buylla A (1999b) Regeneration of a germinal layer in the adult mammalian brain. Proc Natl Acad Sci USA 96:11619-11624.

Doetsch F, Petreanu L, Caille I, Garcia-Verdugo JM, Alvarez-Buylla A (2002) EGF converts transit-amplifying neurogenic precursors in the adult brain into multipotent stem cells. Neuron 36:1021-1034.

Emsley JG, Hagg T (2003) Endogenous and exogenous ciliary neurotrophic factor enhances forebrain neurogenesis in adult mice. Exp Neurol 183:298-310.

Garcia AD, Doan NB, Imura T, Bush TG, Sofroniew MV (2004) GFAPexpressing progenitors are the principal source of constitutive neurogenesis in adult mouse forebrain. Nat Neurosci 7:1233-1241.

Gregg C, Weiss S (2005) CNTF/LIF/gp130 receptor complex signaling maintains a VZ precursor differentiation gradient in the developing ventral forebrain. Development 132:565-578.

Hatta T, Moriyama K, Nakashima K, Taga T, Otani H (2002) The role of gp130 in cerebral cortical development: in vivo functional analysis in a mouse exo utero system. J Neurosci 22:5516-5524.

He F, Ge W, Martinowich K, Becker-Catania S, Coskun V, Zhu W, Wu H, Castro D, Guillemot F, Fan G, de Vellis J, Sun YE (2005) A positive autoregulatory loop of Jak-STAT signaling controls the onset of astrogliogenesis. Nat Neurosci 8:616-625.

Heinrich PC, Behrmann I, Haan S, Hermanns HM, Muller-Newen G, Schaper F (2003) Principles of interleukin (IL)-6-type cytokine signalling and its regulation. Biochem J 374:1-20.

Hitoshi S, Seaberg RM, Koscik C, Alexson T, Kusunoki S, Kanazawa I, Tsuji S, van der Kooy D (2004) Primitive neural stem cells from the mammalian epiblast differentiate to definitive neural stem cells under the control of Notch signaling. Genes Dev 18:1806-1811.

Holmberg KH, Patterson PH (2006) Leukemia inhibitory factor is a key regulator of astrocytic, microglial and neuronal responses in a low-dose pilocarpine injury model. Brain Res 1075:26-35.

Jankowsky JL, Patterson PH (1999) Differential regulation of cytokine expression following pilocarpine-induced seizure. Exp Neurol 159:333-346.

Kerr BJ, Patterson PH (2004) Potent pro-inflammatory actions of leukemia inhibitory factor in the spinal cord of the adult mouse. Exp Neurol 188:391-407.

Kerr BJ, Patterson PH (2005) Leukemia inhibitory factor promotes oligodendrocyte survival after spinal cord injury. Glia 51:73-79.

Kokoeva MV, Yin H, Flier JS (2005) Neurogenesis in the hypothalamus of adult mice: potential role in energy balance. Science 310:679-683.

Lim DA, Tramontin AD, Trevejo JM, Herrera DG, Garcia-Verdugo JM, Alvarez-Buylla A (2000) Noggin antagonizes BMP signaling to create a niche for adult neurogenesis. Neuron 28:713-726.

Magavi SS, Leavitt BR, Macklis JD (2000) Induction of neurogenesis in the neocortex of adult mice. Nature 405:951-955.

Maslov AY, Barone TA, Plunkett RJ, Pruitt SC (2004) Neural stem cell detection, characterization, and age-related changes in the subventricular zone of mice. J Neurosci 24:1726-1733.

Menn B, Garcia-Verdugo JM, Yaschine C, Gonzalez-Perez O, Rowitch D, Alvarez-Buylla A (2006) Origin of oligodendrocytes in the subventricular zone of the adult brain. J Neurosci 26:7907-7918.

Minami M, Maekawa K, Yamakuni H, Katayama T, Nakamura J, Satoh M (2002) Kainic acid induces leukemia inhibitory factor mRNA expression in the rat brain: differences in the time course of mRNA expression between the dentate gyrus and hippocampal CA1/CA3 subfields. Brain Res Mol Brain Res 107:39-46.

Molne M, Studer L, Tabar V, Ting YT, Eiden MV, McKay RD (2000) Early cortical precursors do not undergo LIF-mediated astrocytic differentiation. J Neurosci Res 59:301-311.

Morshead CM, Reynolds BA, Craig CG, McBurney MW, Staines WA, Morassutti D, Weiss S, van der Kooy D (1994) Neural stem cells in the adult mammalian forebrain: a relatively quiescent subpopulation of subependymal cells. Neuron 13:1071-1082.

Morshead CM, Craig CG, van der Kooy D (1998) In vivo clonal analyses reveal the properties of endogenous neural stem cell proliferation in the adult mammalian forebrain. Development 125:2251-2261.

Nakatomi H, Kuriu T, Okabe S, Yamamoto S, Hatano O, Kawahara N, Tamura A, Kirino T, Nakafuku M (2002) Regeneration of hippocampal pyramidal neurons after ischemic brain injury by recruitment of endogenous neural progenitors. Cell 110:429-441.

Parras CM, Galli R, Britz O, Soares S, Galichet C, Battiste J, Johnson JE, Nakafuku M, Vescovi A, Guillemot F (2004) Mash1 specifies neurons and oligodendrocytes in the postnatal brain. EMBO J 23:4495-4505.

Pitman M, Emery B, Binder M, Wang S, Butzkueven H, Kilpatrick TJ (2004) LIF receptor signaling modulates neural stem cell renewal. Mol Cell Neurosci 27:255-266.

Rao MS, Sun Y, Escary JL, Perreau J, Tresser S, Patterson PH, Zigmond RE, Brulet P, Landis SC (1993) Leukemia inhibitory factor mediates an injury response but not a target-directed developmental transmitter switch in sympathetic neurons. Neuron 11:1175-1185.

Shimazaki T, Shingo T, Weiss S (2001) The ciliary neurotrophic factor/leukemia inhibitory factor/gp130 receptor complex operates in the maintenance of mammalian forebrain neural stem cells. J Neurosci 21:7642-7653. 
Smukler SR, Runciman SB, Xu S, van der Kooy D (2006) Embryonic stem cells assume a primitive neural stem cell fate in the absence of extrinsic influences. J Cell Biol 172:79-90.

Sriram K, Benkovic SA, Hebert MA, Miller DB, O’Callaghan JP (2004) Induction of gp130-related cytokines and activation of JAK2/STAT3 pathway in astrocytes precedes up-regulation of glial fibrillary acidic protein in the 1-methyl-4-phenyl-1,2,3,6-tetrahydropyridine model of neurodegeneration: key signaling pathway for astrogliosis in vivo? J Biol Chem 279:19936-19947.

Sugiura S, Lahav R, Han J, Kou SY, Banner LR, de Pablo F, Patterson PH (2000) Leukaemia inhibitory factor is required for normal inflammatory responses to injury in the peripheral and central nervous systems in vivo and is chemotactic for macrophages in vitro. Eur J Neurosci 12:457-466.

Sun Y, Zigmond RE (1996) Leukaemia inhibitory factor induced in the sciatic nerve after axotomy is involved in the induction of galanin in sensory neurons. Eur J Neurosci 8:2213-2220.

Suzuki S, Tanaka K, Nogawa S, Ito D, Dembo T, Kosakai A, Fukuuchi Y
(2000) Immunohistochemical detection of leukemia inhibitory factor after focal cerebral ischemia in rats. J Cereb Blood Flow Metab 20:661-668.

Viti J, Feathers A, Phillips J, Lillien L (2003) Epidermal growth factor receptors control competence to interpret leukemia inhibitory factor as an astrocyte inducer in developing cortex. J Neurosci 23:3385-3393.

Williams RL, Hilton DJ, Pease S, Willson TA, Stewart CL, Gearing DP, Wagner EF, Metcalf D, Nicola NA, Gough NM (1988) Myeloid leukaemia inhibitory factor maintains the developmental potential of embryonic stem cells. Nature 336:684-687.

Wright LS, Li J, Caldwell MA, Wallace K, Johnson JA, Svendsen CN (2003) Gene expression in human neural stem cells: effects of leukemia inhibitory factor. J Neurochem 86:179-195.

Zhu M, Oishi K, Lee SC, Patterson PH (2001) Studies using leukemia inhibitory factor (LIF) knockout mice and a LIF adenoviral vector demonstrate a key anti-inflammatory role for this cytokine in cutaneous inflammation. J Immunol 166:2049-2054. 